\title{
ENTRAMADOS SENSIBLES EN UNA MATINÉ DE QUILMES: UNA MIRADA INTRODUCTORIA
}

\author{
CONFABULAÇÕES SENSÍVEIS NUMA MATINÊ DE \\ QUILMES: UM OLHAR INTRODUTÓRIO
}

\author{
Rafael Andrés Sánchez Aguirre* \\ Gabriela Romina Cigoj ${ }^{* *}$
}

\begin{abstract}
RESUMEN
Este trabajo presenta algunas ideas exploratorias acerca del estudio sociológico de las sensibilidades que se tejen en una matiné de la ciudad de Quilmes, en la Provincia de Buenos Aires. Se trata de un ejercicio investigativo que se encuentra en una etapa inicial y de ajuste. Abordaremos este fenómeno, su música y sus bailes, a través de los relatos surgidos en entrevistas semi-estructuradas realizadas a tres mujeres -de diferentes generaciones- que allí asistieron. Asumimos que la matiné funciona como territorio de acondicionamiento generacional frente a futuras "dinámicas de adultez". Intentamos reconocer modos en que la música y el baile remiten a regulaciones corporales que se traducen en comportamientos y prácticas sociales. Hemos dado amplio espacio a las voces de nuestras entrevistadas para detallar modulaciones sensibles de sus experiencias, proponemos igualmente algunas notas críticas -sobre esas voces- en estado embrionario. El artículo está organizado en tres secciones, la primera presenta brevemente nuestros referentes conceptuales, la segunda es una reconstrucción sociohistórica de Quilmes, la tercera reúne letras de canciones-hits, secciones de las entrevistas y nuestros apuntes de análisis.
\end{abstract}

Palabras-clave: Sensibilidades. Matiné. Quilmes. Adolescencia. Regulaciones emotivas.

\section{RESUMO}

Este trabalho apresenta algumas ideias exploratórias sobre o estudo sociológico das sensibilidades que são tecidas numa matinê da cidade de Quilmes, na província de Buenos Aires. Trata-se de um exercício de pesquisa que se encontra num em estágio inicial e em processo de ajuste. Abordamos o fenômeno de uma festa entre adolescentes, sua música e a dança deles, através das narrações que surgiram em entrevistas semi-estruturadas realizadas com a três mulheres -de gerações diferentes- que participaram do evento. Assumimos que a matinê funciona como um território de adaptação geracional em termos das posteriores "dinâmicas da vida adulta". Tentamos reconhecer modos em que a música e a dança aludem a regulações corporais que se traduzem em comportamentos e práticas sociais. Pautamo-nos no posicionamento de nossas participantes para detalhar as modulações sensíveis de suas das experiências; também propomos

\footnotetext{
"Becario Postdoctoral del Consejo Nacional de Investigaciones Científicas y Técnicas de Argentina. Investigador del Centro de Investigaciones y Estudios Sociológicos-CIES.

"Estudiante avanzada de la Licenciatura en Sociología de la Universidad de Buenos Aires.
} 
algumas notas críticas (sobre essas vozes) em estado inicial. O trabalho está organizado em três seções, a primeira apresenta brevemente nossas referências conceituais, a segunda é uma reconstrução sócio-histórica de Quilmes, a terceira inclui canções-hits, seções das entrevistas e nossas notas de análise.

Palavras-chave: Sensibilidades. Matinê. Quilmes. Adolescência. Regulação emocional.

Este trabajo presenta algunas ideas introductorias acerca del estudio sociológico de las sensibilidades que se tejen en una matiné de la ciudad de Quilmes en la Provincia de Buenos Aires, en este lugar hemos recurrido a los relatos ofrecidos por tres mujeres participantes de estas fiestas. Como se trata de un ejercicio investigativo que se encuentra en sus inicios, buscamos proponer algunas líneas exploratorias y reflexivas de carácter conceptual, socio histórico y musical. A través de las opiniones de las entrevistadas re-conocemos las letras de canciones populares y las tramas del sentir que se tejen en las dinámicas de socialización en espacios de festividad adolescente. El escrito está organizado en tres secciones, la primera presenta brevemente algunos referentes conceptuales desde los cuales sostenemos nuestra perspectiva de análisis, la segunda consiste en una reconstrucción sociohistórica del partido de Quilmes, la tercera presenta un análisis crítico de canciones-hits entrelazadas con las voces de nuestras entrevistadas.

Debemos resaltar que este trabajo hace parte de una prueba piloto que queremos ampliar en el futuro próximo y que ahora nos sirve como marco para afinar nuestras inquietudes. En esta dirección, nuestros argumentos e ideas son exploratorios antes que concluyentes, probablemente el lector encontrará nuestro desarrollo temático en forma "incompleta" y tal vez sentirá nuestro permanente interés por reconocer aspectos estructurales dentro de la dinámica social que estudiamos. Con ello señalamos que no buscamos generalizar ingenuamente a partir de casos particulares; entre las tres mujeres entrevistadas, sino que indagamos por los factores grupales que sus voces nos indican.

\section{Notas conceptuales}

Cuando caminamos por las calles de nuestra ciudad es posible encontrarsenos con una escena que nos constata un proceso social de construcción de nuestras sensibilidades, esta escena es muy sencilla y cotidiana.-Sucede cuando vemos a un niño -acompañado por su madre- con sus pantalones totalmente abajo y orinando la llanta de un auto, también sucede cuando una niña hace lo mismo al lado de un árbol mientras un adulto intenta cubrirla. Estos ejemplos marcan una diferencia entre lo que puede hacer un niño y lo que sería vergonzoso para la mayoría de adultos (al menos en occidente). Este hecho llama nuestra atención acerca de mundos que se han ido constituyendo a través de la historia y que tienen que ver con los niños, los adolescentes y los jóvenes. Mundos en los que se dan diferentes grados de regulación de los impulsos emotivos, que son espacios de goce, formación, preparación, socialización, control, ajuste normalizador y de disrupción. Por lo general, estos mundos generacionales son desconocidos por los adultos de cada sociedad, uno de ellos es el que nos interesa tematizar introductoriamente en esta ocasión, es el mundo de los adolescentes que asisten a una matiné de Quilmes en la Provincia de Buenos Aires, Argentina.

Philippe Ariès (1987), en su libro El niño y la vida familiar en el Antiguo Régimen, sostiene que el descubrimiento de la infancia se dio en el periodo que va del siglo XIV al XVI, como parte de un proceso que estuvo relacionado con la conformación de espacios de educación, acompasados con la fundación y afirmación de la familia moderna, que sirvieron como núcleos de disciplina protegidos por la justicia y la policía. Nosotros consideramos que se trata de un proceso de larga duración que aún continúa, y 
a diferencia de Ariès no pensamos que existió un período ideal en el que los niños simplemente (de forma equitativa) hacían parte del mundo adulto y que fueron despojados de tal participación con la aparición de nuevas instituciones. "De la misma manera en que ocurre con frecuencia en las visiones románticas, Ariès también percibe del pasado ante todo aquello que puede colocarse como bueno frente a lo malo del tiempo propio" (Elias, 1998, p. 426).

Por nuestra parte, entendemos que hubo un cambio en las relaciones de poder entre padres e hijos que devino en la consolidación de espacios propios de acuerdo a cada momento de la vida, allí fueron ganando una mayor autonomía relativa niños, adolescentes y jóvenes. "En la época moderna, el niño paulatinamente resulta apartado del mundo de los adultos y es remitido por muchos años a una especie de isla juvenil de la sociedad. El cuarto de niños, la escuela, [la matiné,] los movimiento juveniles y, no por último, la vida estudiantil forman parte de sus símbolos" (Elias, 1998, p. 425). En el proceso de hacerse adultos los niños atraviesan espacios diseñados para aprender de acuerdo a un modelo social, allí se pone en juego una manera de vivir constituida por ellos (de acuerdo a sus necesidades) y que es diferente a la de las generaciones mayores. "La reflexión más profunda acerca de las necesidades características de los niños es, en el fondo, el reconocimiento de su derecho a ser comprendidos y apreciados en su carácter propio" (Elias, 1998, p. 410).

En esta dirección, intentamos escuchar con atención las voces de tres mujeres, quienes nos cuentan algunas de sus experiencias en una fiesta adolescente, como acceso para reconocer este mundo desde una perspectiva sociológica procesual de las sensibilidades. Sus canciones y sus bailes nos sirven como guía para conocer dimensiones emotivas/ corporales desde las cuales se van figurando sentidos sociales. En la trama sonoro-bailable tratamos de distinguir matices de las regulaciones activadas, de las desregulaciones permitidas y de la forma en que recrean, reproducen o replantean el mundo adulto que les rodea e interpele.

En relación con la idea de "música" que manejamos aquí, sabemos que existen diferentes formas de conceptualizar lo que se entiende con tal término y que tales formas están ligadas a ritmos colectivos histórico-culturales. Más allá de ser considerada habitualmente como un "[a]rte de combinar los sonidos de la voz humana o de los instrumentos, o de unos y otros a la vez, de suerte que produzcan deleite, conmoviendo la sensibilidad, ya sea alegre, ya tristemente" (DRAE, versión online), nosotros pensamos que la música tiene que ver con emociones -entendidas como procesos que conjugan factores biosociales- que son aprendidas y que son transformadas en sonidos (re)creados y (des)organizados (Sánchez Aguirre, 2014).

Así, entendemos la música como una forma de combinación sonora que se encuentra ligada -en diversos grados- con la combinatoria de las relaciones sociales (Blacking, 1973; Simmel, 2003). Sería impreciso asegurar que la música es necesariamente un reflejo de las relaciones de una sociedad, más bien asumimos que funciona como testimonio (y potencia de trasformación) de las formas de interrelación puestas en juego y de las sensibilidades que adquieren un carácter sonoro. Tal testificación puede reconocerse fácilmente en las letras musicales, en los bailes, del mismo modo que la encontramos en las diferentes formas de pronunciación y acentuación vocal de los colectivos humanos -que en tanto musicalidades, son indicadores del sentir de sus integrantes-. ${ }^{1}$

El baile, en este marco, es asumido como parte de una dimensión musical correspondiente al desarrollo de movimientos corporales figurados en la experiencia grupal e individual de las sonoridades. Entendemos que los pasos de baile están vinculados con formas de sentir la música en relación intersubjetiva, es decir que asumimos que existe una sensibilidad musical-bailable que desborda a la pura experiencia estética individual. El baile individual se presenta entonces en interdependencia con modulaciones coreográficas del sentir y del hacer grupal. El sentir revelado en el gesto y en el movimiento corporal refiere, más allá de la experiencia subjetiva y sus posibles "formas emotivas internas", a codificaciones

\footnotetext{
${ }^{1}$ Podemos recordar que Semán y Vila (2011) recurren a las líricas como medio de recreación de los equilibrios entre los sexos, detallando los modos de recepción y corporeización de la cumbia en medio de discursos abiertamente sexualizados. Por su parte, Varela y Alabarces (1988) estudian el rock argentino como ejemplo musical popular que se constituye en práctica de resistencia, en voz de los sectores subalternos.
} 
de la experiencia musical colectiva y a la moral que deviene en pasos bailables (Janesick, 2008; Scribano, 2012, 2014). Dado que existe una amplia conceptualización acerca del tema de la danza y de la música no pretendemos dar cuenta de toda ella, más bien nos concentramos en el acceso que puede darse desde la experiencia de la música en la matiné y las marcas morales que se traducen en formas de baile.

Igualmente, asumimos que las sensibilidades son como una unidad relacional en la que se conjugan percepciones, sensaciones y emociones en sintonía con diagramáticas de la actitud y formas de ser corporal, sensibilidades desde las cuales se estructuran grupos, individuos y relaciones de poder (Elias, 1998; Scribano, 2009a). Consideramos que el estudio de las emociones en el campo de la sociología, como lo sugiere Scribano (2009b), ha sido abordado por diversos teóricos desde diferentes ángulos. Descartes, Spinoza, Comte, Bentham y Marx, entre otros, han sugerido perspectivas en las que las reflexiones acerca del cuerpo y las emociones se tornan referentes estructurantes de sus trabajos; aunque tales temáticas no resultan evidentemente protagónicas, deben ser leídas y reconocidas en cierta clave: aclarando la forma en que se presenta lo corporal en vinculo con la maneras de regulación de comportamientos o conductas. ${ }^{2}$

En esta línea, pensamos que las emociones/ sensibilidades de las personas adultas consisten en construcciones sociales en las que los modelos de reacción "fijados biológicamente" han sido modificados a través de procesos de aprendizaje y de (auto)regulación de los impulsos (Elias, 1998; Sánchez Aguirre, 2013). De tal forma, es desde la infancia que empezamos a vivir una dinámica de sintonización emotiva de acuerdo a la clave del grupo social al cual pertenecemos -por ejemplo, en algunas sociedades sus integrantes se presentan

\footnotetext{
${ }^{2}$ Siguiendo a Scribano, puede decirse que "existen diversas maneras de sistematizar las orientaciones teóricas en las que se fundan los estudios sobre los cuerpos y emociones. Una posible, teniendo en cuenta el contexto latinoamericano y sin pretensiones de exhaustividad, es la siguiente: a) una línea de trabajo ligada a Foucault y sus conceptos de control, disciplinamiento y tecnologías del yo; b) un enfoque conectado a Bourdieu y sus nociones de habitus, hexis corporal y espacio social; c) un conjunto de investigaciones en el campo de lo biopolítico que refieren a Esposito, Agamben, por un lado, y a Negri y Hardt, por otro; y d) las indagaciones que, desde una visión post-colonial, retoman a la corporalidad como pista para un pensamiento contra-hegemónico" (2009b, p. 412).
}

más abiertos al contacto físico, mientras que en otras tal contacto es visto como un asunto agresivo-. Cada etapa etaria (infancia, adolescencia, juventud, adultez, vejez) en cada sociedad exige un ajuste de los comportamientos de acuerdo a codificaciones de lo que se considera como "correcto" o "incorrecto". Así, la adolescencia podemos entenderla como un momento del proceso de educación emotiva delimitada por un conjunto de actitudes y patrones de comportamiento que viven las persona en su trayecto hacia la adultez (Chaves, 2006).

\section{Contexto de un proceso}

Quilmes es el nombre que sirve para identificar a una ciudad y al Partido que la contiene, ubicados en la Provincia de Buenos Aires y a 17 kilómetros de la Ciudad de Buenos Aires sobre la costa de Rio de la Plata. La segunda fundación de Buenos Aires en 1580, por Juan de Garay, ofrece una primera referencia al territorio de Quilmes, en medio de la repartición de terrenos que conformaron algo así como "estancias". Éstas fueron inicialmente treinta y se distribuyeron sobre la costa del Riachuelo hasta las proximidades de lo que se llamó pago de la Magdalena. Para tal momento existía un asentamiento indígena Guaraní en las costas del actual río Don Bosco. Es en este período que se va conformando una idea de la Argentina gaucha y ganadera, como parte de una figura identitaria vinculada a las vaquerías y a los grandes rodeos realizados a campo abierto - uno de ellos, considerado de los primeros, tuvo lugar en las tierras del actual Partido de Quilmes (Lombán, 1992). ${ }^{3}$

En estos años la costa fue utilizada para el contrabando de mercancías y la trata de esclavos africanos (Studer, 1984). Asimismo, sucedió el intercambio de manufacturas por productos agrícolaganaderos que estaban en crecimiento. Un hecho relevante en la fundación del primer poblamiento ocurre en 1665, cuando arribaron los indios Kilmes después de un violento desterramiento que ejerció el gobiernoespañol.Estosindígenas fueron desplazados desde los valles Calchaquíes, en la actual provincia

\footnotetext{
${ }^{3}$ La reconstrucción histórica presentada en esta sección usa datos extraídos de la página del Municipio de Quilmes: http://www.quilmes.gov.ar/.
} 
de Tucumán (antigua provincia del imperio Inca), hacia Córdoba, para continuar posteriormente hacia Buenos Aires. Así, fueron obligados a trasladarse $1.500 \mathrm{~km}$ a pie, en condiciones paupérrimas, como castigo por la resistencia que ejercieron frente a las fuerzas imperiales durante algo más de un siglo (Lombán, 1992).

Las familias de indígenas que llegaron después del largo recorrido fueron obligadas a asentarse en las barrancas del Río de La Plata. En 1666 ellas conformaron el primer poblado al sur del Riachuelo y fue conocido como la Reducción de la Santa Cruz de los Indios Kilmes. Alrededor de la capilla se aglomeraron los humildes ranchos de barro y paja. La zona de influencia de la capilla se extendió rápidamente hacia otros poblados $\mathrm{y}$, en contra de lo dispuesto en el reglamento de la creación de la Reducción, fueron estableciéndose otros pobladores no indígenas. En el año 1780, la zona fue dividida en tres áreas: Quilmes (que llegaba hasta Ensenada y comprendía las actuales Avellaneda, Lomas de Zamora, Florencio Varela, Berazategui y La Plata, luego con el transcurso del tiempo estas zonas se fueron separando), Magdalena y San Vicente. En 1784 la "Parroquia de Quilmes" pasó a denominarse "Partido de Quilmes".

Las ventajas geográficas del territorio, que se caracterizaba por ser un lugar de fácil desembarco y muy cercano a la Ciudad de Buenos Aires, hicieron de la costa quilmeña no solo un espacio atractivo para el comercio, sino que se constituyó en un escenario de enfrentamientos bélicos. Por ejemplo, el 25 de junio de 1806 más de 1.500 ingleses arribaron y ocuparon las barrancas. Otra invasión desembarcó sus tropas en Ensenada el 28 de julio de 1807, la llegada de los ingleses fue difícil ya que debieron atravesar seis kilómetros de unos terrenos cenagosos (que se encontraban inundados) hasta encontrar su primer campamento en la zona actualmente denominada La Plata. Desde allí, ellos tenían que atravesar varios arroyos hasta encontrar a la reducción de los Quilmes y después debían cruzar el Riachuelo, trayecto que sumaba unos cincuenta kilómetros. Se cuenta que todos los habitantes de la zona lucharon impidiendo que las tropas inglesas avanzaran.
Después de tales choques las tierras de Quilmes fueron vendidas o prácticamente "regaladas" a miembros distinguidos de la Ciudad de Buenos Aires. Muchos de los nuevos propietarios instalaron en esa zona sus casas de fin de semana. Además aparecieron nuevos pobladores, criollos $\mathrm{y}$ españoles, quienes se dedicaron a comerciar y contrabandear productos derivados del ganado, asunto que alentó la economía local a través de la organización de estancias. En 1852 Quilmes vivió nuevas divisiones, de allí surgió Barracas al Sur (hoy partido de Avellaneda). En 1861 se separa Lomas de Zamora y en 1873 Almirante Brown, ambas convertidas en partidos. En 1891 se conforma Florencio Varela y el último en lograr la autonomía municipal fue Berazategui en 1960. Estas divisiones pueden entenderse como parte del crecimiento de diferentes núcleos urbanos y de los ajustes políticoadministrativos correspondientes.

Entre 1872 y 1873 llegaron a Quilmes el tranvía de tracción animal, el ferrocarril y el telégrafo. A su vez, en los costados de las vías férreas comenzaron a establecerse algunas fábricas. Otras iniciativas fabriles acontecen a partir de 1888 cuando se instala la Cervecería y Maltería Argentina de Quilmes - que con el tiempo llegó a ser reconocida como una de las más importantes del mundo (Lombán, 1992). Este último caso es significativo, no sólo por sus niveles de producción, que desde el inicio superaron al total de lo producido por las demás fabricas del país, sino que se consituyó en una fuente importante de trabajo y un pilar identitario para el partido (y muy probablemente para la nación). Esta tendencia continuó con la creación de otras fábricas como la Cristalería Rigolleau en Berazategui, la Maltería en Hudson, y la papelera de la Compañía General de Fósforos en Bernal.

Tal impulso económico facilitó, en los años posteriores, la paulatina aparición de diferentes iniciativas industriales cerca de los caminos o del recorrido del tranvía eléctrico. El avance industrial estuvo acompañado por la creación de barrios obreros, varios de ellos cercanos a las plantas de producción, desde allí se fue urdiendo el poblamiento de la ciudad y de sus periferias. De esta manera fueron conformándose La Colonia (Quilmes Oeste) y Bernal Oeste. En este sentido, la población urbana del partido llegó a superar los tres cuartos de su total 
en 1916, revirtiendo la situación de años anteriores cuando solo uno de cada cuatro habitantes vivía en la ciudad.

Debemos resaltar también que, durante la primera mitad del siglo XX hasta la década de los sesenta, Quilmes fue la primera ciudad balnearia que recibió visitantes de forma masiva. Inicialmente fueron las franjas medias y altas de la sociedad porteña bonaerense las que la visitaron, sólo a mediados de los años cuarenta los sectores populares llegaron como turistas, tal situación estuvo ligada al desarrollo automotor que facilitó el traslado de los sectores más acomodados hacia la costa Atlántica -a nuevos balnearios como Mar del Plata (Lombán, 1992).

Con la instalación de nuevas fabricas -en el transcurso de los años treinta- como Textilia S.A., La Bernalesa, Rhodia y Ducilo, acompasada con el mejoramiento general de la infraestructura productiva de la ciudad, se alentó la llegada de nueva población, muchos de ellos inmigrantes europeos que sirvieron como mano de obra. Este dinamismo económico hizo que en 1935 la ciudad fuese considerada como uno de los tres centros industriales más importantes de la provincia y uno de los cinco de todo el país. Para 1946, Quilmes contaba con más de 700 fábricas. Esta tendencia industrializadora alentó el proceso de migración interna, desde el campo hacia la ciudad, lo que generó una alta demanda de vivienda que no pudo ser cubierta por el gobierno, cuestión que redundó en el crecimiento de asentamientos marginales. En la actualidad, aunque el crecimiento industrial no volvió a tener las mismas proporciones de la primera mitad del siglo XX, los problemas habitacionales siguen vigentes y el partido es uno de los más poblados del conurbano con 582.943 habitantes (INDEC, 2010).

Hoy Quilmes está compuesto por distintas localidades: Quilmes, Bernal, Don Bosco, Ezpeleta, La Florida y San Francisco Solano. Cada una de ellas está organizada internamente de acuerdo a divisiones barriales y clasificaciones sociales. Así, por ejemplo, en una misma localidad encontramos zonas de emergencia habitacional, otras afectadas por la contaminación industrial, unas fuertemente marginadas y denominadas villas de emergencia, al igual que zonas residenciales de clase media y sus correspondientes corredores comerciales, todo esto compone un paisaje urbano contrastante que se hace evidente al transitar sus calles.

Si tenemos en cuenta los rasgos históricos que hemos señalado acerca de Quilmes, con los que sus autoridades y líderes alientan -en tiempos recientesla construcción de una imagen ideal colectiva, resulta evidente que éste ha sido un lugar de fuerte dinamismo económico. Tal vez esta condición ha funcionado como velo principal, como parte de una mitología, que no permite ver otras dimensiones de la vida de su comunidad. Allí se cruzan fuerzas históricas ligadas a culturas indígenas abusadas, a choques imperiales entre españoles e ingleses, a disputas criollas que pretendían la "independencia", a la imposición de dinámicas industriales que alentaron la llegada de nuevos pobladores, al auge de una imagen de prosperidad y de turismo que fue posteriormente desplazada. Todos estos factores fueron marcando un carácter colectivo modelado a través de diferentes regulaciones: como colonia, como estancia, como industria.

Consideramos que, el énfasis industrial que se hace de Quilmes, más allá de las críticas sobre la reducción que esta idea puede suscitar, sirve como guía para entender lo que nosotros queremos mostrar aquí. Creemos que, en el proceso de ajuste social con miras al acople económico-industrial, la sociedad de Quilmes fue estableciendo una disciplina laboral que tuvo como contracara la existencia de espacios de "desregulación socio-emotiva" a través de la fiesta. Una pista que nos lleva a esa consideración la encontramos en la matiné, lugar donde los hijos de los trabajadores viven una especie de entrenamiento para el futuro. Es decir, los adolescentes asisten a ellas en medio del cumplimiento de sus obligaciones -principalmente relacionadas con la asistencia a una institución educativa.

En esta línea, debemos resaltar que somos conscientes de la reciente aparición del concepto "adolescencia" y de los rápidos cambios vividos en las formas de socialización juvenil, al igual que de la flexibilización de las condiciones laborales. Aunque podemos asumir que ha habido un cambio en las formas del trabajo y del disfrute personal/ social, también podemos asegurar que existe una tendencia regulatoria que entrena a los adolescentes para adaptarse a las nuevas condiciones de trabajo y 
a las formas validas de disfrutar su tiempo libre. $\mathrm{La}$ matiné nos da pistas sobre esta reflexión y nos abre un abanico de sentidos ligados a cambios culturales, sociales y sentimentales, en este punto el baile y la música funcionan como dispositivos para el análisis sociológico.

\section{Tres mujeres nos cuentan sus experiencias sobre música y baile}

El lugar al que nos referiremos se llama Super Club, a inicios del año 2014 se llamaba Space, éste ultimo nombre lo tuvo desde el 2011. Tal espacio bailable existió desde mucho antes bajo el nombre de Elsieland -fundado en 1964 y cerrado en el 2010. A pesar de los cambios de nombre su infraestructura sigue siendo similar. Está situado sobre la avenida Calchaquí en Quilmes Oeste, a cuarenta cuadras de Quilmes centro, en una zona muy transitada y que conecta con partidos aledaños como Florencio Varela, Berazategui y La Plata. La zona de este boliche (discoteca) está compuesta por varios negocios, una que otra fábrica y algunos bares que son más pequeños y menos prestigiosos (a estos últimos concurren personas que buscan otro tipo de fiestas, ó aquellas que no son admitidas para bailar en Super Club). El barrio es de casas bajas en su mayoría, algunas viviendas son más modestas que otras y también se encuentran dúplex remodelados, la mayoría de sus habitantes son de clase media. Esta caracterización del barrio se mantiene a través de las calles que le siguen a Quilmes centro hasta llegar al boliche, pero a medida que uno se aleja -a 10 cuadras más o menos- es posible encontrarse con zonas más humildes hasta llegar a la localidad de San Francisco Solano.

El local bailable es bastante concurrido y reconocido, aunque en sus inicios solo admitió personas mayores de edad, resulta llamativo que una de nuestras entrevistadas señaló que la edad no fue un factor tan determinante como si lo fue (y tendríamos que revisar si lo sigue siendo) la vestimenta. En las últimas tres décadas y hasta el día de hoy, el lugar dio apertura a una matiné para adolescentes, en ella parece existir una mayor flexibilidad de admisión. El baile, la música de moda y el encuentro entre personas de generaciones similares (en este caso menores de edad entre los
12 y 16 años principalmente) activa dimensiones afectivas y de interacción entre los sexos que consideramos interesantes de tratar, ya que nos remiten a un mundo al que los adultos no tenemos acceso usualmente.

Veamos la experiencia que tres mujeres, de tres generaciones distintas, han tenido acerca de la matinée de Super Club (Elsieland o Space). Proponemos que estas tres versiones sean entendidas procesualmente y no como meras experiencias aisladas, es decir, que cada caso nos haga pensar en sus interconexiones con los demás casos, a la vez que vamos aclarando las figuras sociales materializadas en la subjetividad de estas personas. De tal forma, asumimos que la experiencia individual, más allá de las críticas relativistas que puedan plantearse, se presenta como síntesis de una clave social estructural. Como se trata de un ejercicio exploratorio e introductorio, daremos mayor resonancia a las voces de las entrevistadas mientras sugerimos algunas notas críticas para pensar sus perspectivas. ${ }^{4}$

La estrategia que seguimos consiste en presentar el transcurso que va desde la generación más antigua a la más reciente, la generación más antigua corresponde a una mujer de 34 años al día de hoy, la siguiente corresponde a una mujer de 24 años y la más reciente tiene actualmente 14 años. Presentamos inicialmente las canciones-hits de cada generación (canciones populares en términos de su masividad no solo local, sino regional y nacional), seguidas de opiniones relativas al baile y las experiencias de socialización de estas personas en la fiesta adolescente.

\subsection{Mujer de 34 años}

De esta persona podemos decir, a modo de presentación, que actualmente se desempeña como abogada y trabaja en una entidad gubernamental, es soltera, se autoreconoce en una posición social de clase media, vive en uno de los mejores barrios de la zona y eventualmente visita Super Club en la noche. Ella asistió a la matiné a mediados de los años noventa. Nos contó que dos canciones muy

\footnotetext{
${ }^{4}$ Las entrevistas fueron realizadas durante los meses de febrero y marzo de 2014. Se han omitido los nombres de las entrevistadas por petición suya. 
escuchadas en su época adolescente fueron Vete de aqui de Los Chakales, y Pienso en Ti del grupo Red. La primera canción nos cuenta lo siguiente,

Me toco enamorarte a ti / ya no quiero, ya no quiero tus mentiras / que el amor que me has dado a mi / fue menos que tu hipocresía, mi vida // Hoy al fin te conozco yo / tú eres dueña, dueña de mis sentimientos / y que mucho nos amábamos / tú causaste mi sufrimiento, lo siento // CORO: Quédate aquí o vete de mi lado / devuélveme el amor que te di, / dime que sí o no me digas nada / y si estas enamorada de mi // Vete de aquí, de mi lado / y que no sepan que he llorado por ti / dime que si, o no me digas nada / vete ya niña mimada de aquí // Hoy aquí yo te di mi amor tú eres mala, / tú eres mala compañera / que si no me vas a querer vete / y búscate quien te quiera, de veras.

Es evidente que esta canción posee un fuerte carácter romántico, asunto que no diferirá en la segunda canción, lo que puede indicar la construcción de la exaltación de la relación amorosa entre hombre y mujer como tópico central de la vida, recordemos que estamos hablando de un ambiente de adolescentes. Preguntamos a la entrevistada, " $-i \zeta$ cómo se bailaba?", ella respondió: “-Separados, no agarrados con el sexo opuesto o con amigas, sino que separados, pequeños pasos cortos, pequeños movimientos de brazos". Seguimos preguntando,

Gabriela: -¿La mayoría de las canciones que me dijiste eran de cumbia, como se bailaba?

Mujer de 34: -Vete de mi lado, la de Los Chacales, había una parte que hacías pasos para adelante y después hacías saltitos para atrás y era muy cómico, muy gracioso, para nada sensual por ejemplo pero era divertido, todos nos divertíamos, teníamos 13, 14 años y estábamos a los saltitos bailando y haciendo payasadas, moviéndonos para un lado y para el otro, para adeltante y para atrás saltando y es muy divertido.

G: ¿¿Creés que había alguna diferencia entre la forma que bailaban las mujeres y los hombres?

M: -¿Diferencias de sexo no de épocas?

G: -Claro...

M: -Eh... las chicas eran de dar más vueltitas, las mujeres suelen hacer movimientos más sexys, las mujeres suelen como menear mas hasta debajo de manera sensual.

G: -¿En esa época?

M: - y actualmente...

G: $-¿ \mathrm{Y}$ en esa época era asi?
M: -Si, después hay quien baila con mas movimiento o se baila mejor o peor pero era así pero en sí la diferencia entre sexo era... si se bailaba un tema de salsa y era de a dos, un chico y una chica, el chico, el hombre puede llegar a guiar un poco más en general en todos los casos y guía un poco más para las vueltas y eso y en la cumbia, pero sí las mujeres más vueltitas les dan, el hombre le hace dar más vueltitas y eso fundamentalmente en el baile, meneo hasta abajo y se pone mas como objeto de deseo de alguna forma.

En este caso podemos encontrar un orden relacional ligado al disfrute y al relajamiento social, tanto la letra como el baile afirman unas relaciones "convencionales" entre hombres y mujeres, es decir, del hombre guiando a la mujer y haciéndola girar a su propio ritmo e intenciones. La mujer en sus movimientos se presenta como seductora, sexy, cumpliendo roles promovidos desde el mundo de los adultos, en esta medida la matiné funciona como espacio reproductor de un orden social en el que los adolescentes deben aprender a manejarse para que en su adultez puedan ser considerados como "normales". Tal normalidad va a estar asociada con movimientos correctos -por ejemplo, menear mucho las caderas femeninas está bien, pero en un hombre esta acción puede resultar socialmente perjudicial. Veamos ahora la segunda canción, que también enfatiza un sentido romántico,

Pienso en ti solo pienso en ti / desde que te conocí yo de ti me enamore // Pero tu juegas, con mi amor / sabes que muero por ti no me niegues tu querer // Nunca mas, nunca mas de ti me podré olvidar / (dale dale red, dale dale red) // CORO: No podré olvidarme de ti porque ya eres parte de mi / yo no lo puedo aceptar que ya no voy a verte jamás / no podré olvidarme de ti porque ya eres parte de mi / yo no lo puedo aceptar que ya no voy a verte jamás.

Frente a esta sugerencia musical de la entrevistada nosotros indagamos sobre el tema del baile como estrategia para descubrir corrimientos sensibles, sincopas vivenciales de su mundo adolescente. Así, preguntamos,

Gabriela: -¿Algunos de los pasitos que me nombraste tenían nombre?

Mujer de 34: -Que recuerde no, salvo el meneaito que se hacía en la canción que ahora también pasan 
en fiestas o bailes también pasan el meneaito que vas hasta abajo meneando, que se basa en eso y el pasito que hacías era con ese nombre.

G: - ¿Y que era el meneaito?

M: -Menear con las caderas hacia un lado y hacia el otro de manera sensual...

G: $-¿$ Y por qué eso sería sensual?

M: -(risas, más risas...) y yo diría que es porque está moviendo las partes pudendas. Capaz que da para imaginarse temas eróticos con el sexo opuesto.

G: -¿Y eso vendría a ser en el lugar de las mujeres o los hombres también meneaban en esa época...? M: -Menos, capaz que se veía menear más a la mujer...

G: - ¿Y en ese meneo que hacía el hombre?

M: -Y había de todo, por ejemplo Leo mi amigo se ponía a menear pero no era muy sexy, pero bueno, pero se ponía a menear...

G: - ¿Y qué actitud tomaba el hombre si la mujer meneaba? O cuando daba una vuelta como vos me dijiste...

M: -¿Qué actitud? De espectador que se yo, miraban ehh, les gustaba, se ponía en algún punto como objeto de deseo a la mujer, entonces como que les gustaba, también en la tarima se subían mas las mujeres.

G: -¿Pero no pasaban mas allá del rol de espectador? ¿No avanzaban más allá de eso en el baile?

M: -No, no, en general no...salvo en los bailes de espuma que había algún que otro toquetón, pero en general no...no se veía tanto.

Aquí volvemos a ver el señalamiento permanentemente del lugar del hombre y de la mujer, la mujer moviendo su cuerpo y el hombre contemplando, afianzando el rol que a cada cual le corresponde. Allí se resalta la condición emotivaimpulsiva de la mujer y racional-contemplativa del hombre. En esta última línea vale la pena señalar que en Argentina existe una fuerte tendencia masculina de participación moderada (o "limitada") en el baile (al menos en generaciones que van desde los 45 años hasta las más jóvenes) -asunto que se hace más claro si lo comparamos con hombres de sociedades como la colombiana o la brasileña ${ }^{5}$. No

\footnotetext{
${ }^{5}$ Bien podría objetarse que el Tango es un ejemplo histórico que contradice lo dicho en relación con la quietud del hombre argentino, sin embargo podemos recordar que hasta hace muy poco tiempo este género musicalbailable ha mantenido un carácter coreográfico claramente (rígidamente) definido, asunto que para generaciones más nuevas ha resultado poco
}

negamos que en las fiestas se viva una algarabía, relajamiento y desorden colectivo (por ejemplo, es muy usual que hagan el "trencito" como parte de una "buena fiesta") sino que el rol masculino es mucho más pasivo comparado con otras latitudes de Suramérica. Tal condición masculina no implica un mejor posicionamiento de las mujeres, simplemente indica un equilibrio de poder diferente entre los sexos. Asunto que valdría la pena explorar con más detalle en otro escrito.

Al tratar de indagar otros niveles de socialización, la entrevistada comenteó lo siguiente,

Gabriela: -¿Había alguna diferencia entre la gente que circulaba en los distintos espacios del boliche? Mujer de 34: -Puede ser, no pero, en general predominaba la informalidad.

G: - ¿Y la vestimenta en relación a esto la veía homogénea?

M: -Sí, podía haber alguien o grupos o dentro del mismo grupo que se arreglase un poco más, yo en general me arreglaba más dentro del grupo, pero en líneas generales predominaba más la informalidad...

G: -¿Había distintas clasificaciones en cuanto a la ropa o a tal comportamiento tal vez?

M: -Y siempre estuvo el tema de quien podía ser mas cheto $^{6}$ o menos cheto pero creo q no se veían las diferencias actuales, creo que están más marcadas ahora, lo veo un poco mas así.

G: - ¿Pero había una valoración en cuanto a la vestimenta?

M: -Sí, un poco, un poco se puede decir que había un grupo podía decirse como mas marquero, va grupo o personas, un poco sí pero no se veía al extremo la diferencia tan marcada, no la veía tan marcada.

G: -¿Había alguna denominación que podías decir se utilizaba?

M: -Y no, chetos por ahí...

G: -¿Y por escuchar algún estilo de música había alguna denominación?

atractivo ya que demanda unas destrezas y una alta disciplina. Aunque muchos jóvenes argentinos bailan Tango, probablemente son muchos más los que no están interesados por este asunto y se inclinan por otros géneros musicales como, por ejemplo, el rock. Pensamos que este posicionamiento masculino también puede estar ligado con las mitologías nacionales que conectan a este país con Europa, en esta línea se promueve una autoimagen colectiva nacional e internacional que se acompasa mejor con la actitud de una persona racional, pausada y moderada, mientras que la euforia la impulsividad y el desenfreno pueden caracterizar mejor a un habitante netamente latinoamericano.

${ }^{6}$ Termino que se refiere a alguien que es ó aparenta ser adinerado y que se comporta como una persona de una posición social alta, distinguida o selecta. 
M: -Menos... siempre estaba el que no le gustaba un estilo de música, la cumbia... y podía llegar a subestimar a los que escuchen ese estilo, no solo en lo que se usaba de bailar, porque ya el tema que se usen las canciones de esos grupos que estaban ya era una moda que se usaba, no quedaba como que tapaba la moda, que se escuche o se baile en el momento no era que estaba fuera de la moda, estaba dentro, ya que alguien la escuche para bailar o en todo momento puede ser que lo vería como mas mersa, bajo.

G: -¿Había clasificación?

M: -No sé si por música, no sé, no me acuerdo que alguien podría decir como que villero ${ }^{7}$ como se dice ahora... pero no recuerdo que sea tan marcado como después fue.

G: - ¿Y eso se notaba en la dinámica del boliche? M: -No, capaz que en esos bailes era como mas homogéneo todo, debía haber supongo bailantas ${ }^{8}$, lo que se llamaba...

G: - ¿Y pero en las matiné?

M: -Ahí estamos hablando de las matinés, que van a ir de colegios públicos, privados y todo eso, se veía homogéneo, no había bandas de sectores sociales muy marcados.

G: - ¿Importaba la ropa o no era muy importante?

M: -No era importante para nada, ni tenia clasificación. No podía ver alguien q le guste más el rap, o alguien que le guste más la cumbia, un gordito pero no era tan importante, pero poco no eran tan marcado no es que se discriminaba un grupo con otro, bastante homogéneo.

En estos comentarios de la entrevistada vemos acentuado un carácter de homogeneidad acerca de la composición social de la matiné, esto puede deberse a varios factores. Algunos de éstos podrían ser: -la anulación inconsciente que esta persona hace del paisaje que reconstruye idealmente, -que probablemente la matiné estuvo 'destinada a' y 'asociada con' determinado sector social, -que el filtro socioeconómico del local comercial fue efectivo. En esta línea, la discriminación no se presenta como problemática en la medida que los participantes de la fiesta hacían parte de una misma clase, tal vez las alusiones a la cumbia, el rap o a alguien "gordito" dejan ver que esas apariciones no fueron problemáticas en la medida

\footnotetext{
${ }^{7}$ Forma despectiva usada para denominar a personas que viven en barrios marginales de la ciudad.

${ }^{8}$ Lugares o fiestas de baile popular, principalmente de música tropical.
}

que no amenazaron al 'establecimiento vivencial' de quienes se consideraban como iguales.

\subsection{Generación mujer de 24 años}

La segunda entrevistada es estudiante universitaria, vive con sus padres y trabaja eventualmente en actividades comerciales, planea irse a vivir con su novio en los próximos meses, se considera a sí misma como una persona de clase media. Ella asistió a la matiné de Elsieland a mediados de la primera década del siglo XXI, sus opiniones nos muestran un panorama complementario respecto al que obtuvimos en la primera entrevista. Esta persona indicó que dos canciones importantes de su vivencia fiestera adolescente fueron La lata de Supermerk2, y Toma la mema de El empuje; aquí presentamos las letras,

\section{LA LATA}

CORO: Si tu viejo es zapatero... / zarpale la lata, I se se, I zarpale la lata // (corre guachin ${ }^{9} . .$. $y$ las manitos ahi $y$ ahi $y$ ahí.. supermerk2, supermerk $2 \ldots$ y ahora... suene el rototo... suene el rototo) // Salto la ficha en el barrio / todos los pibes me andan buscando / ya se enteraron que anoche me rastrie / de la casa del zapatero una lata de P.V.C // a la lata... al latero... se la zarpe al zapatero //Y ahora los pibes andamos viajando / y el que quiere que le convide / que levante las manos / (sueprmerk2, supermerk2) //

\section{TOMA LA MEMA}

Eh Guachin vacilaaa!!! ESO!!! // CORO: $A y$ nena, a tu cola le falta crema / a tu boca una mamadera / y los pibes te la vamos a dar / Alcen las manos, alcen las manos, alcen las manos // Ay nena, a tu cola le falta crema / a tu boca una mamadera / y los pibes te la vamos a dar / alcen las manos, le vamo a dar! // CORO // Quiero tu cola nena / Vení movela / Agachadita, agachadita, despacito toma la mema, / toma la mema Toma la memaaa (Mové tu cola) // Quiero tu cola nena / Vení movela / Agachadita, agachadita, / despacito Toma la mema, toma la mema Toma la memaaa. // El Empuje!

\footnotetext{
${ }_{9}$ Termino que se usa en forma cariñosa para referirse mutuamente entre amigos de barrio (marginal), otros sectores sociales lo usan para referirse a una persona desgraciada o malintencionada.
} 
Si comparamos estas canciones con las sugeridas por la primera entrevistada, encontramos un innegable cambio sociomusical en sus liricas -mientras las dos primeras tratan temas eminentemente románticos, las últimas dos se presentan en una clave social villera (del barrio marginal). Si revisamos los videos de estas canciones encontramos también un cambio en el formato de la presentación personal de los artistas. En las primeras las coreografías de los músicos y sus cabellos largos (que emulan al ambiente rockero) son modificadas -en las segundas- por cabellos cortos, con una vestimenta (que contiene elementos raperos) al igual que unos movimientos corporales más informales (algunos más eróticos y otros relacionados con los movimientos de brazos de las barras de futbol). ${ }^{10}$ Así, de un lado tenemos al grupo tropical (también denominado de 'bailanta') que es formateado de acuerdo al gusto de la clase media blanca-tomando distancia de los rasgos negros y pobres del sonido de la cumbia (Cragnolini, 2006), mientras que en un segundo momento encontramos la irrupción de la cumbia villera sin ningún filtro y recibida por esos mismos sectores sociales que la estigmatizan. Cuando preguntamos a nuestra entrevistada sobre el baile, esto nos contó,

Gabriela: -¿Qué movimientos predominaban en el baile?

Mujer de 24 años: -En los bailes... movimiento de cadera, y un énfasis en lo que hacía la mujer... las canciones eran generalmente cantadas por bandas de cumbia masculinas que hablaban de la mujer... se ponía énfasis era en que la mujer mueva las caderas, menee, de vueltas...

G: -¿Cómo describís el baile?

M: -Se bailaba generalmente en grupos de amigos, grupos por sexo, separados, pero también podía mezclarse, y se daba el acercamiento o mediante que el varón saque a bailar a una chica... a la cual generalmente le hacía dar vueltas tomado de la mano como luego meneando los dos, o directamente la aproximación se podía dar si el hombre venia a menearte de atrás, en tal caso la chica podía aceptar o no, la chica también podía ir y hacer lo mismo pero era más extraño, en algunos grupos mal visto, en otros no. Sino directamente

\footnotetext{
${ }^{10}$ Para comparar los videos puede usar estos enlaces, uno de música tropical argentina https://www.youtube.com/watch?v=Agv4d59eku0 y otro más de cumbia villera https://www.youtube.com/watch?v=_p8pfNzbm9E.
}

mediante un amigo o él mismo podía preguntarte si "daba para un trance". En todo caso se aceptaba o no.

G: -¿Podían ir más allá del baile?

M: -Mmm... pues empezaba a no ser tan mal visto que se den besos con más de una persona en la noche, aunque dependía de los grupos y las personas como lo tomasen. Lo que más predominaba era bailar entre amigos es decir reírse, joder con las letras, hacer pasos de acuerdo a ellas, cuando se bailaba entre amigos generalmente los hombres movían mucho las manos se bailaba más que nada sueltos, podían menear pero no moviendo tanto las caderas como las mujeres y digamos que todo en tono de risa, levantando las manos, agitándolas al compás de la canción que sonase.

G: -¿Habían diferentes formas de bailar?

M: -Había diferencia entre los tumberos ${ }^{11}$ como bailaban... había un movimiento más desenfadado, parecía más despreocupado, levantando la cabeza y manos con el dedo índice para arriba de manera pausada pero el ritmo de la música y los pies al mismo ritmo, los demás normales y chetos también lo podían hacer o no, pero más para el lado de la diversión o parodia no como algo que los identificase con la letra. El pasito de los tumberos parecía más sentido. En el caso de las tumberas hacían el mismo paso pero moviendo mas la cadera y con movimientos más exagerados de meneo.

G: $-¿$ Los que bailaban de formas diferentes bailaban juntos?

M: -Los grupos se podían mezclar sobre todo los varones, pero chicas también... había ondas diferentes pero hasta cierto punto se podían compartir salvo alguna que otra mirada mala, entre ellos ese rato... los chetos generalmente no eran de mover demasiado el cuerpo y si lo hacían más parodiando que otra cosa, aunque alguna cheta generalmente se copaba en la movida sobre todo en la tarima... a veces en la pista principal había dos jaulas dispuestas para que en su mayoría chicas entren y estén bailando... los varones se subían generalmente a hablarles, salvo algunos casos que ellos subían para bailar y parecían disfrutar de eso.

G: -¿Cómo surgían los pasos de baile?

M: -En el caso del reggaetón cuando empezó casi todos lo bailaban igual sobre todo tal vez las

\footnotetext{
${ }^{11}$ Usualmente conocida como una palabra del ambiente carcelario o referente a experiencias de tal contexto. La agrupación de cumbia villera Yerba Brava, en su canción Tumbero, presenta a una persona tras las rejas que enfrenta con temeridad las situaciones de su vida.
} 
mas cumbieras $^{12}$ tal vez movían o "perreaban" como se empezó a decir movimiento rápido para adelante y para atrás de la pelvis o moviendo los pies golpeando contra el piso y sacudiendo la cola... todas tratábamos de imitar los pasos de los videos que llegaban en esa época, pero tal vez las más atrevidas, las cumbieras... o las normales lo hacían moviéndose más, o las otras casi no lo hacían seguían bailando con pasos más suaves moviendo el cuerpo para un lado y el otro, o estos mismos pasos pero más suavizados, no tan bruscos.

Dos aspectos principales nos interesa resaltar sobre estas respuestas, uno relacionado con las posibilidades de desregulación de impulsos que se daba entre los participantes de la matiné, otro vinculado al encuentro social que este espacio de fiesta habilitaba. Frente al primer aspecto podemos decir que la desregulación de impulsos, del acercamiento afectivo entre hombres y mujeres, se dio en medio de un contexto económico de incertidumbre y tensión; es decir, pensamos que los adolescentes tuvieron la posibilidad de experimentar más abiertamente sus besos y movimientos corporales como parte de un mecanismo de fuga de presión que su sociedad estaba viviendo. En otras palabras, las desregulaciones económicas, de las fronteras comerciales nacionales, estuvieron acompasadas con desregulaciones a nivel micro que permitieron el ascenso y amplificación de voces antes no escuchadas, por ejemplo, de los sectores menos favorecidos cantando a favor de sustancias ilegales y de prácticas corporales más flexibles, u otro ejemplo, de los adolescentes de diferentes condiciones económicas compartiendo más abiertamente sus bailes, sus gestos y sentimientos.

Tal situación no implicó que la estigmatización cediera, o que los conflictos sobre la acumulación de la riqueza en pocas manos se replantearan, sino que más bien aconteció una evitación del conflicto social vía la flexibilización de la regulación de impulsos más básicos. Los adolescentes replicaron en cada caso, en los noventas y en la primera década del nuevo siglo, figuras que sus padres y su sociedad sostuvieron, aunque los adolescentes contaron con mayores grados de autonomía (a través del

\footnotetext{
${ }^{12}$ Personas que gustan la cumbia y que usualmente son relacionadas con ambientes sociales marginales.
}

reconocimiento de sus derechos y en comparación con chicos de su misma edad, por ejemplo, de mediados del siglo XX) su mundo era permeado por los modelos sociales que los adultos reproducían. En todo caso no dejøó de ser un asunto alarmante para las generaciones más adultas, muchos de ellos padres en ejercicio que consideraron tal desregulación como algo aislado y que no les sucedía a sus propios hijos. Esta práctica adolescente pudo empujar, sin proponérselo, hacia nuevas formas de comprensión o asunción de las relaciones afectivas interpersonales. En cuanto a las formas de socialización, podemos volver nuevamente a la voz de la entrevistada,

Gabriela: -¿Cómo estaban divididos los grupos en la fiesta?

Mujer de 24 años: -Los grupos estaban divididos en tumberos, no tumberos, más normal, chetos. Los tumberos se vestían con la nueva onda de aquel entonces que se veía en la cumbia villera pos Damas Gratis, muy marcada en los varones sobre todo, en las chicas que por ajustarse un poco más el pantalón jean o de tela de avión, el mismo flequillo con mechones finitos separados sobre la frente y pelo largo con una cola y zapatillas deportivas y una actitud un poco mas suelta en cuanto a gestos y forma de relacionarse... tenían una pose que era más de enfrentamiento, de ir de frente. En cuanto a los hombres se les exigía en peinados corte taza con flequillos separados finitos los mechones sobre la frente, pantalón de tela de avión y campera del mismo material, zapatillas deportivas, y en algunos casos medias arriba del pantalón.

G: -¿Como percibían los demás esta vestimenta?

M: -Eso era estar mal vestido para la mayoría o todo el resto que no era de la onda, y estaba más cercana a lo normal, a lo que las revistas y medios mostraban como modelos a imitar y se sentía que eso estaba bien que así debía vestirse. O quedaba canchero pero no groncho, dígase grasa, berreta, villero. Había gente que ni estaba tan apegada a esto ni a la otra onda, que se podían considerar más normales, no marqueros ni deportivos ni chetos.

G: -¿Pero, estas personas más cercanas a la cumbia villera no usaban "ropa de marca"?

M: -Eran marqueros también de la ropa deportiva pero lo adecuaban a su modo de combinar y disponer de los elementos... esto sobre todo yo lo vi más acentuado cuando iba a matiné época del 2003 a 2005, donde todavía las letras de cumbia villera más crudas se escuchaban, después siguió la 
división pero ya no tan marcada, de hecho nuevos grupos que empezaban a escuchar electrónica, los que en el 2008 se convertirían algunos en floggers, zapatilla all star, pantalones de colores, eran chetos pero no clásicos e inventaban pasos nuevos saltando, agitando las manos y donde también el consumo de algunas sustancias incitaba.

G: -¿Qué podés decir de las chetas y su vestimenta? M: -Las chetas de ese momento se vestían con jean, o calzas y polleras, tableadas, con volados, según el año de moda alguna remera con algún corte de algodón o modal, alguna inscripción, zapatillas, botas boxeadoras, toda esta vestimenta hacia diferenciar a como se vestían en otros bailes para adultos, es decir uno no se vestía como una nena, pero tampoco como adulta, quedaba canchero vestirse así, esa era la forma, sino eras mirada como que no encajabas o eras una boludita.

Con estas opiniones podemos confirmar un encuentro de clases en el que cada una de éstas, representadas por sus adolescentes, buscó la distinción social; no significa que la generación anterior (de la primera entrevistada) no viviese tal ejercicio de diferenciación sino que seguramente existió un diferencial de poder mayor que no permitía el acceso de aquellos adolescentes que integraban grupos con menos ventajas sociales, en la fiesta de Elsieland.

De otra parte, cuando los marginados compraron una prenda de vestir "propia" de los establecidos, entonces la cuestión del valor social no recayó en la posesión del objeto, sino en el uso que se le dio y la elegancia con la que se portó. Estos aspectos remiten a mecanismos muy elaborados del autocontrol corporal, que son afianzados por los adultos en sus ejercicios de establecimiento/marginación (podemos pensar en el "correcto" movimiento de las manos o de la voz para ser reconocidos como personas elegantes, una exageración de más o una palabra inadecuada y se descubre nuestra posición social), y que los niños integran cada vez más rápido en sus vidas a través de múltiples medios (televisión, internet, escuela, barrio, etcétera).

\subsection{Generación mujer de 14 años}

Nuestra última entrevistada es una chica que actualmente va a la escuela y su experiencia de la matiné es vigente, vive con su familia en un barrio residencial considerado de los mejores de la zona. Ella mencionó dos canciones muy escuchadas en las fiestas, una fue Soy Soltero de El Dipy, otra Tírate un paso de Los Wachiturros ${ }^{13}$, veamos las letras,

\section{SOY SOLTERO}

AAHH... Todos los solteros con las palmas arriba... / Todos los solteros con las palmas arriba... / Si sos casado tomate el palo... / Si sos casado tomate el palo... RAAAH // Y esto es... el dipy papá! Ah!... // CORO: Ay que lindo es ser soltero... / Como me gusta vivir todo el día al pedo... / No trabajo y no estudio porque no quiero... / Hay que lindo es ser "soltero"... // En el baile las pibas me dicen que soy feo... (FEO) / No me importa porque ser lindo no quiero... (RE FEO) / Vení turra, vení que te meneo (BUENO) / Yo te re doy porque estoy soltero... Yo te re doy porque estoy soltero... // RAAHH // Si sos soltera vení movela / Si estas casada no pasa nada... / Tu novio no está, ponete re zarpada... / ese gil está durmiendo vení meneala / Porque esta noche te hago separar!

\section{TÍRATE UN PASO}

CORO: Esta noche los cumbieros levanten los brazos / los wachiturros tiren pasos (bis) // tirate que? tirate un paso / tirate un 'ro' tirate un paso / tirate que? tirate un paso / tirate un 'ro' tirate un paso / va para adelante y tirate un paso // Este movimiento pa que mueva el ojete / muévelo muévelo mueve el cachete / tenes la cola grande y estas pa comerte / muévelo muévelo mueve el cachete / este movimiento pa que mueva el ojete / muévelo muévelo mueve el cachete / tenés la cola grande y estas pa comerte / muevelo muevelo mueve el cachete / muévelo hasta el bajo muévelo si tienes novio déjelo // CORO // Me encanta salir de noche / yo no lo temo a la oscuridad /

\footnotetext{
${ }^{13}$ Debemos señalar que este nombre deriva de dos términos del lunfardo como lo son guacho y turro. Los dos términos pueden usarse de maneras distintas según la intención y el contexto de enunciación. El primero -de origen quechua- puede entenderse como una forma cariñosa para referirse mutuamente entre amigos del barrio (también puede usarse como nombre para designar un persona mala o una persona lista), el DRAE lo define como un adjetivo para señalar que una persona es huérfana. El segundo término usado con mala intención puede referirse a una persona maliciosa o aprovechada -también puede significar que alguien es haragán, pesado, contradictorio o tonto. En el caso del nombre de la agrupación creemos que buscan jugar con los sentidos de los dos términos, combinándolos para resaltar su propia viveza y destreza comercial-musical.
} 
un wachiturro más de noche salimos para baile mujeres discoteca bailoteo / un wachiturro más las mujeres se dejan envolver el ritmo te monta atrevido / un wachiturro más de noche salimos para baile mujeres discoteca bailoteo / un wachiturro más las mujeres se dejan envolver el ritmo te monta atrevido // Toma toma toma por guacho / atrevido toma toma te confundiste conmigo / toma toma toma por guacho / atrevido te voy a dar // Ella quiere látigo turro dame látigo / ella quiere látigo turro dame látigo látigo látigo.

En estas líricas encontramos una referencia más concreta respecto a la ruptura del orden social que planteaban las canciones de la primera entrevistada (y que acentúan la línea temática que planteaban las canciones de la segunda entrevistada), para nuestra adolescente los temas musicales de la mujer más adulta resultan desactualizados y sosos. Aquí sucede algo similar a lo que nos pasa cuando pensamos en los comportamientos de nuestros abuelos, de quienes sus movimientos y gestos nos parecen llamativos, más asombroso resulta cuando ellos nos cuentan cómo expresaban sus afectos en la juventud. Seguramente sus comportamientos (los de los abuelos) nos parecen anticuados y tal vez rígidos. De tal modo, la comparación nos permite considerar cómo los mensajes melosos y dramáticos de las primeras canciones (de la mujer más adulta) resultan graciosos y pasivos frente al mensaje erótico directo que plantean las dos últimas canciones (de la chica de 14 años). Al preguntar sobre los modos del baile, la entrevistada nos conto lo siguiente,

Gabriela: -¿Podés comentarme algo sobre los pasos de baile?

Mujer de 14 años: -Y con los de cumbia que se yo moviendo el pie tipo haciéndose ademanes haciéndose el cumbiero, es gracioso, por ahí decís mucho la cumbia no, pero en ese momento agarras pies, caderazo mucho manos reboleando, cantando a lo loco.

G: - ¿No hay para el paso un nombre?

M: -Ehhh meneo no sé... perreo, levantamiento de mano, que sé yo... no sé, paso turro, desde el hit Tirate un paso de los Wachiturros quedó el paso... G: $-i Y$ de los hits de ahora? Cuales serian los pasos?

M: -Traqueteo de las culisueltas traka traka traka, creo que si traqueteo, perreo, meneo, también dicen un paso piola, algunos dicen así... algunos no todo el mundo. Los turros dicen ehh tirate un paso piola (dramatización con tonito de voz). No sé, perreo, meneo, sandungueo.

G: - ¿Y el reggaetón?

M: -Y no sé qué sé yo estas ahí meneas, yo no meneo aclaro eh! Pero lo veo de la gente que lo hace y es a ver (de nuevo baila), la cadera agarras y se mueve para un lado y para el otro haciendo círculos.

G: $-¿ Y$ en el caso de la cumbia, nadie hace los pasitos que hacen las bandas de moda?

M: -Naa si, en realidad los que bailan mejor hacen los pasos de moda, o sea partieron de base de eso, o sea a partir de los Wachiturros, después Las Culisueltas se copiaron, y ahora los que cantan hacen eso, pero no sé cómo describir los pasos, qué sé yo a ver movimiento de manos para abajo y dedo índice moviendo al compas de la canción y los pies dando pasos frenéticos para un lado y para el otro, para el centro, para adentro así todo muy serio que hay gente que lo hace que parece que les están agarrando convulsiones. Las Culisueltas a la vez mueven la cadera de una forma sensual y obscena (risas)... es que capaz hay gente que lo hace más en serio y otra en broma...

G: - ¿En "serio"?

M: -Y que lo sienten, que se sienten identificados con él, que les guste porque en serio les gusta la onda, no porque el paso está de moda, el paso se está usando y que se yo es gracioso, estamos todos bailando el pasito turro.

G: - ¿Y los hombres? Bailan igual que las mujeres? M: -Capaz hacen el pasito mas de cumbia, no mueven la cadera, sería un poquito gay, no sé afeminado, no es que tenga nada en contra de los gays, pero no se mueven así sino los cargan los amigos.

G: -¿En la dinámica de baile hay grupos bailando de amigos y parejas, cómo es?

$\mathrm{M}$ : - $\mathrm{Y}$ con amigos es en broma, estas meneando pero no estás levantándote a nadie, que se yo. Es como que estás jugando, boludeando, riéndose. En el caso de chicas yo vi casos que lo hacen para provocar, en el caso de chicos siempre los vi riéndose. $\mathrm{Y}$ a los chabones les gusta más ver dos chicas bailando perreando, no sé qué pasará por sus mentes, no me quiero imaginar, pero como el caso de las chicas no se no me gusta ver dos chicos perreando.

G: -¿En la dinámica del baile, cuánto dirías que es estar con los amigos y cuándo estar de levante? M: -Depende, hay gente que está con los amigos y gente que está sacando flacas o flacos. Supongo que mitad-mitad o mezclados no sé. Hay veces 
que bailan de más de dos, gente que baila uno acá otro acá y una en el medio, o al revés.

G: -¿Ah sí? Contame eso.

M: -Por ejemplo hay veces que bailan un chabón, una chabona y un chabón, o un chabón y dos chaboncitas, hay veces que las dos chaboncitas son amigas y no se los van a tranzar.

E: - ¿Entonces decís que eso queda en la situación de baile o...?

M: -Si hay onda entre algunos y que se yo depende, la mayoría de la veces no, a veces sí... si hay onda, siguen...

G: - ¿Y los chicos cómo te intentan levantar? Qué movimiento hacen para levantarte?

M: -Qué sé yo mueven el traste y la cadera de una manera sensual, si eso se puede llamar sensual, se le ponen atrás del traste de una flaca y la intentan apoyar los pobrecitos...

G: $-¿$ Y en el caso de las chicas?

M: -Las chabonas se hacen las sensuales mientras están bailando con cara de tipo "ay que sexy que soy" y el chabón de tipo "ay soy tan macho"

G: -¿Con qué expectativas se va a Space?

M: -A levantar, también a pasarla bien con amigos pero la mayoría a levantar y por ahí a otro lugar vas con la expectativa y no se cumple, ahí sabés que se va a cumplir.

Encontramos tres elementos para resaltar en las opiniones de esta adolescente. El primero relativo al uso del "paso turro", del paso de baile, como una muestra de la permeabilidad que viven los sectores medios a través de los productos sonoros populares. Esta influencia de lo marginal es filtrada en el juego de la simulación que estos chicos de clase media desarrollan, pues a pesar del disfrute que conlleva repetir los pasos de una agrupación musical de chicos villeros, la entrevistada confirma que existen unos niveles de "compromiso bailable", de "seriedad", que afirman los posicionamientos sociales. Ella por ejemplo, dice participar de forma medida $\mathrm{y}$ momentánea, mientras que hay otros que sí lo incorporan como parte de una diferenciación. De otro lado, otro elemento para destacar está relacionado con el reconocimiento de la homosexualidad y unos ajustes homofóbicos que le corresponden, así, existen modos del baile que son validos en el paisaje fiestero -pero dos hombres bailando reggaetón no son concebibles o desagradables (claro, como lo dice nuestra adolescente, todo está bien con los gay, se les respeta siempre y cuando no se noten en la escena $)^{14}$. Un tercer elemento para pensar está relacionado con el cambio en las maneras del acercamiento entre hombres y mujeres, sus cruces y dinámicas, para nosotros el baile "de a tres" es indicativo de movimientos grupales hacia nuevas formas de encuentro afectivo que las nuevas generaciones practican. En relación con estos elementos volvamos nuevamente sobre la voz de la entrevistada,

Gabriela: - ¿Y cuando decís que hay grupos que no se llevan bien por qué lo decís?

M: -Y porque te andan mirando tipo "eh..." que se yo, por ahí te miran mal porque usas tal ropa o tal zapato. Y bueno sobre todo las chicas que te miren mal por usar tal ropa o que se combine mal pero no importa no te van a golpear en los otros lugares. Igual en Space casi no te miran mal, o no te golpean... aparte, no hay mucha pelea ahí, alguna vez me miraron mal pero nunca me hablaron. No fue por las chicas que dejé de ir sino por los chabones.

G: - ¿Los sitios que dejaste de ir fue por los que denominaste turros?

M: -Sí. No sé, me gusta más la música que pasan en otra parte o no sé o no hay tanto descontrol tanto, no sé, es otra onda. Otra onda hay turrocheto, mediano.

G: - ¿Eso se ve en Space?

M: -Sí, en Space hay de todo, se ve turro-cheto, mediano, cheto, pero por ahí hay más cantidad de turros medianos, no medianos-chetos.

G: $-¿ Y$ esto diferencia las matineés?

M: -Claro, por ahí entras puede haber algún turro, pero hay mas chetos. En Space están más mezclados. Pero en los otros hay turros también y está bien no se sentían mal, pasa que no es su onda.

G: -¿Y qué diferencia hay en la música que pasan ahí con otros lugares?

M: -En los otros pasan cumbia, pero por ahí mas electrónica.

G: - ¿Y en qué se diferencian en otras cosas?

M: -Que en Space se dan todos con todos, es una cosa espantosa, yo vi cada cosa, que se yo andan bailando ahí de forma obscena (risas) y chapándose ${ }^{15}$ pero de a 2 , no de a uno, así como

\footnotetext{
${ }^{14}$ En este punto es interesante pensar en la relación entre asco y normalidad social, ya que las reacciones homofóbicas van acompañados de formas de repulsión condicionadas grupalmente de acuerdo a estructuras de normalidad establecidas (Elias, 1989).

${ }^{15}$ Besarse apasionadamente.
} 
una cosa mucho descontrol, una desesperación de hormonas, dios mío!

G: -¿Por qué decís mucho?

M: -Mucho porque es mucha cantidad, la mayoría, no todos.

G: - ¿Todos con todos o entre parejas que se quedan toda la noche?

M: -Naa todos con todos, hay algunos que se quedan toda la noche, pero es lo menos. Querés tomar... (canción de cumbia que comenzó a cantar la entrevistada).

Vemos entonces que la manifestación de impulsos emotivos presenta diferentes niveles de regulación si los comparamos generacionalmente, tal (des)regulación está acompasada con la integración de diferentes sectores sociales y la aceptación de la manifestación de actitudes más "animalescas"-ello no implica que nosotros las consideremos buenas o malas. Creemos que más allá de los diferentes niveles de integración (social, económica, moral, emotiva) se siguen manteniendo figuras de establecimiento/ marginación que se reproducen en diferentes niveles. La estigmatización no deja de ser un factor clave en el proceso, de tal modo es posible para los adolescentes participar, vivir, bailar la música villera pero afianzar asimismo los lugares que a cada cual le corresponden. La entrevistada señala que hay otros espacios bailables donde no se vive tanto descontrol, en los que se escucha más música electrónica y algo de cumbia, y que en general es preferible un turro-cheto (la emulación sofisticada de un pobre) que mezclarse en el espectáculo del desborde. Tales valoraciones de la entrevistada no se encuentran por fuera de la estructura social a la cual pertenece, a los flujos de una voz grupal (aparentemente más democrática) que reconoce en lo marginal una humanidad llena de exoticidad pero sin despojarla de su condición indigna y ordinaria.

\section{A modo de conclusión}

Hemos propuesto un recorrido a través de las voces de tres mujeres que asistieron a una matiné de Quilmes. Propusimos algunas ideas críticas acerca de sus experiencias adolescentes (muchas de ellas simplemente quedan abiertas para su discusión y replanteamiento), hemos querido reconocer algunos rasgos de un mundo inaccesible para la mayoría de los adultos. Consideramos que cada uno de estos casos hace parte de un proceso social que remite a momentos de una dinámica sensible, allí las individualidades son sintetizadoras de una clave grupal correspondiente a la sociedad en la que las entrevistadas han crecido. De tal forma, estas personas en su adolescencia vivieron la matiné como una instancia de adaptación hacia la adultez, en la que la experiencia de sus cuerpos y las proximidades estuvo en sintonía con sentidos morales, con geometrías sociales que les indicaban por donde continuar. En todo caso, descubrimos algunas irrupciones que desde la marginalidad influencian y potencian modificaciones de los diferenciales de poder, construyendo formas paralelas de contacto y encuentro.

\section{Referencias}

ARIÈS, P. El niño y la vida familiar en el Antiguo Régimen. Madrid: Taurus, 1987.

BLACKING, J. How musical is man? Seattle: University of Washington Press, 1973.

CHAVES, M. Investigaciones sobre juventudes en Argentina: estado del arte en ciencias sociales. La Plata: IDAES - UNSAM, 2006.

CRAGNOLINI, A. 2006. Articulaciones entre violencia social, significante sonoro y subjetividad: la cumbia villera en Buenos Aires. TRANS-Revista Transcultural de Música, No. 10, 2006.

DRAE. Diccionario de la Real Academia Española. Disponible en: http://www.rae.es/recursos/diccionarios/ drae. [Consultado 3 de febrero de 2014].

ELIAS, N. El Proceso de la Civilización. México: Fondo de Cultura Económica, 1989.

. La civilización de los padres y otros ensayos. Bogotá: Editorial Norma, 1998.

INDEC, Instituto Nacional de Estadística y Censos de la República Argentina. Censo 2010. Disponible en: http:// www.censo2010.indec.gov.ar/

JANESICK, V. La danza del diseño de investigación cualitativa: metéfora, metodolatria y significado. En: DENMAN, A. y HARO, J. (comp). Por los rincones. Antología de métodos cualitativos en la investigación social. Hermosillo: El Colegio de Sonora, 2002.

LOMBÁN, J. Nueva historia de Quilmes. Quilmes: El Monje Editor, 1992. 
SÁNCHEZAGUIRRE, R. A. Apuntes sobre La construcción conceptual de las emociones y los cuerpos. RELACES. No. 13 Año 5, p. 75-86, 2013. Disponible en: http://www. relaces.com.ar/index.php/relaces/article/view/252/192.

SÁNCHEZ AGUIRRE, R. Emociones y Música: sociología de las regulaciones emotivas en la isla de San Andrés. Tesis de Doctorado en Ciencias Sociales (no publicada), Universidad de Buenos Aires. Buenos Aires, 2014.

SCRIBANO, A. Capitalismo, Cuerpo, Sensaciones y Conocimiento: Desafíos de una Latinoamérica Interrogada. En: Sociedad, Cultura y Cambio en América Latina. Lima: Universidad Ricardo Palma, 2009a.

Cuerpo, Emociones y Teoría Social Clásica: Hacia una sociología del conocimiento de los estudios sociales de los cuerpos y las emociones. Cátedra Florestan Fernandes, Clacso, 2009b.

Sociología de los cuerpos/emociones.

RELACES, No. 10, Año 4, 2012.

Entrevista Bailada: Narración de una travesía inconclusa. Intersticios, Vol. 8, $\mathrm{n}^{\circ} 2$, p. 103-112, 2014. Disponible en línea en: http:/www.intersticios.es/ article/view/13778/9056. [Consultado: 25/10/2014].

SEMÁN, P. y VILA, P. Cumbia. Nación, etnia y género en Latino-América. Buenos Aires: Editorial Gorla, 2011.

SIMMEL, G. Estudios Psicológicos y Etnológicos sobre Música. Buenos Aires: Gorla, 2003.

STUDER, E. La trata de negros en el Río de la Plata durante el siglo XVIII. Buenos Aires: Libros de Hispanoamérica, 1984.

VARELA, M. y ALABARCES, P. Revolución, mi amor. El rock nacional 1967-1976. Buenos Aires: Biblos, 1988.

Submetido 09/2014

Aprovado 12/2014

Publ. UEPG Humanit. Sci., Linguist., Lett. Arts, Ponta Grossa, 22 (2): 131-147, jul./dez. 2014 Disponivel em <http://www.revistas2.uepg.br/index.php/humanas> 